Cumhuriyet International Journal of Education-CIJE

e-ISSN: 2147-1606

Vol 6 (1), 2017, $107-122$

\title{
The Effects of Metacognitive Guidance on Self-Regulation Skill in Online Self- Regulated Learning Environment
}

\author{
Serap SAMSA YETİK
}

\author{
Summary
}

\section{INTRODUCTION}

Self-regulation is defined by Pintrich (2000:453) as "an active and constructive process in which students set goals in the light of their past experiences and contextual features of the environment they are in and according to these objectives monitor, regulate and control their cognition, motivation and behaviour". Studies conducted to support selfregulated learning usually argue that these skills can be developed when students are made to participate in interactive discussions to reflect upon their own learning processes and expand multiple visions (Butler, 1995). One of the most essential processes for life long learning is through the metacognitive thinking skills. At this point, the notion of metacognition comes into prominence. Metacognitive support is a support system that aims to increase students' learning skills through systematic teaching (Bannert, Hildebrand and Mengelkamp, 2009). In this sense, the aim of the study in general is to determine how the state of preservice teachers' getting metacognitive support in online self-regulated learning environment affects their self- regulation skills. In the study, it was also investigated whether there was a linear relationship between posttest scores of online self-regulated learning skills and socialization that is perceived in online learning environment.

\section{METHODS}

The study was carried out with $2 \times 3$ factorial design. The sample of the study consisted of 72 preservice teachers studying at their $8^{\text {th }}$ term and having teaching practice course at the department of Computer Education and Instructional Technology at Ankara and Gazi Universities. The study started with 82 students; however, as a result of some dropouts, the study was conducted with the participation of 72 students. In the beginning of the experimental treatment, the locus of control scale was implemented to the students and according to the results gathered from this test, students' locus of control tendencies were determined. Iterative measurements were performed at the beginning and end of the experimental treatment through students' answering the "Online Self-Regulated Learning Scale". At the end of the study, "The Scale of Socialization" that is perceived in online learning environment was benefited so that students could evaluate the social dimension of the online environment.

\section{FINDINGS}

According to the results gathered in the study, the findings of pretest scores of the study indicate that self regulated learning skill differed depending on the students' individual characteristics. The findings reveal that the self regulated learning skills of the students with external locus of control are lower than those of the internals. Another finding of the study suggests that when students whose self regulated skills differed depending on different locus of controls were given metacognitive support by taking their 
individual differences into consideration, the difference between the skills of regulating the learning processes diminishes relatively. In other words, in all of the groups that are given metacognitive support, an increase was observed in online self regulated learning skills. When the scores were examined, the most increase was seen in the group with external locus of control. That the external students were given more metacognitive support enabled them to increase these skills. On the other hand, in the groups that weren't given metacognitive support, no increase was seen in online self-regulated learning skills. In the external group getting no support, a significant difference was found between the pretest and posttest scores of online self-regulated learning skills; however, it was seen that this difference was for the benefit of the pretest. No significant relationship was detected between self-regulated learning and the socialisation perceived in online learning environment. In other words, students, even though they studied collaboratively in the research, didn't perceive the environment as social.

\section{DISCUSSIONS AND SUGGESTIONS}

Preservice teachers' participating in interactive discussion groups in online learning environments is of critical importance in terms of being prepared to the possible situations that they may come across in their future professional career. The reason for this is that, according to Mercier and Frederiksen (2007), while some students are aware that they need more support, some others, although they get support, may not be aware of the inadequacy in their knowledge level. Aleven, Stahl, Schworm, Fischer and Wallace (2003) stated that studies on individual differences can contribute to the design of support systems based on the qualities of target users. In this regard, based on the research into students' individual differences, with the design of different support systems, it is possible to infer that some contributions can be made to gain a variety of learning skills as well as success. Likewise, Mercier and Frederiksen (2007) promoted the idea that the support aimed at the needs of those with different learning profiles can be a suitable design principle for multiple learning environments. The support level that each learner needs to accomplish a task differs and so the most suitable learning design that each learner can make use of is required to be realized. Besides, researchers assert that the interaction of the system with the instructor is also shaped by the individual differences of learners and state that they have reached findings similar to this.

On the other hand, the students with external locus of control compared to others may have less academical success (Jonassen and Grabowski, 1993:352). Self-regulated learning skill has a significant effect on academical success (Zimmerman and MartinezPons, 1988, 1990; Zimmerman and Bandura, 1994; Winne, 1995; Dabbagh and Kitsantas, 2005; Boekaerts and Cascallar, 2006; Narciss, Proske and Koerndle, 2007). Learners with high self-regulation skills prepare a very well organized study environment and study process and that's why they can achieve more success academically. In this sense, the important point is to have students with external locus of control gain more self-regulation skills compared to others and guide them so that they can achieve more. 